\title{
Amarilis y Delia Domínguez: nexos entre dos poetas desde la conciencia de ser mujeres-autoras*
}

\author{
Alida Mayne-Nicholls Verdi**
}

\section{Resumen}

En el presente trabajo, me propongo vincular a dos poetas: Amarilis y Delia Domínguez. La primera es peruana y vivió en el siglo XVII cuando su país era un virreinato que dependía del imperio español. La segunda es chilena y todavía vive. Aunque hay una clara distancia temporal, me parece que las líneas de unión entre ellas atraviesan sus obras y no solo se limitan a características que podríamos considerar más bien superficiales, como el hecho de que ambas son mujeres, americanas y poetas. Mi objetivo es establecer cruces entre sus obras, partiendo desde la premisa de que las dos escriben desde un posicionamiento y conciencia de ser mujer-autora. Para esto, me centraré en Epístola a Belardo de Amarilis y el libro El sol mira para atrás de Delia Domínguez.

Palabras clave: Delia Domínguez, Amarilis, mujeres poetas, conciencia de mujer/autora.

\section{Amarilis and Delia Domínguez: links between two poets from the consciousness of being women authors}

\begin{abstract}
In this paper, I propose a link between two female poets: Amarilis and Delia Domínguez. The first one is Peruvian and lived in the XVII century, when her country was a viceroyalty depending on the Spanish empire. The second one is alive and Chilean. Although there is a clear temporal distance, I think that the connecting lines between them go throug their works, and they are not limited to characteristics that could be considered superficial, as the facts that they are women, Americans and poets. My aim is to establish linkages between their work, starting from the premise that they write from a positioning and awareness of being woman and authors. For this purpose I will concentrate on Amarilis's Epístola a Belardo and Delia Domínguez's El sol mira para atrás.
\end{abstract}

Keywords: Delia Domínguez, Amarilis, female poets, female/author awareness.

* Este artículo forma parte de una investigación sobre la escritura poética de Delia Domínguez, Magíster en Letras mención Literatura, Pontificia Universidad Católica de Chile.

** Magíster en Letras, mención Literatura. Pontificia Universidad Católica de Chile, Santiago, Chile. amayne@uc.cl 


\section{Introducción}

El texto en prosa "Amante lírica y visible" de Delia Domínguez aparece en el libro El sol mira para atrás ${ }^{1}$. En él la poeta chilena destaca a Amarilis como uno de los nombres que forman parte de su genealogía como escritora:

Hacia mediados del siglo XVI se comienza a encontrar nombres de escritores y artistas nacidos en América. Pero, referencias puntuales de mujeres escritoras, aparecen recién en el siglo XVII. Destacan en esa coyuntura temporal Santa Rosa de Lima $^{2}$-quien escribió sencillos y devotos versos intimistas- y otras dos peruanas, Clorinda ${ }^{3}$ y Amarilis, que se desempeñan a la maravilla por los hermosos recovecos de la poesía postrenacentista. (2008: 161)

La lectura del texto de Delia Domínguez, hace surgir mi interés por conectar las escrituras de Domínguez y Amarilis, pero no simplemente desde el hecho de que las dos son poetas y mujeres, sino desde la perspectiva de que construyen un doble posicionamiento. Por un lado, ambas tienen conciencia de que son poetas mujeres y, por el otro, hay conciencia de que están configurando su lugar en el mundo de las letras, es decir, que son autoras.

Amarilis es el seudónimo 4 con el cual escribió la poeta peruana y Epístola a Belardo es la única obra que se conoce de ella. Esta fue publicada en 1621 en el libro La Filomena de Lope de Vega, a quien ella dirigió la carta. Para el presente trabajo, me interesa esta obra lírica no desde la perspectiva de la carta de amor dirigida al autor español, sino desde el punto de vista de una poeta, mujer, que escribe desde la periferia del imperio español. El poema da cuenta de la conciencia que existía en Amarilis de su posición, destacando su condición tanto de género como de peruana, por lo cual me parece importante explicitar esas posiciones, realizando el paralelo con Domínguez.

1 El libro es una antología de poemas y textos en prosa, realizada por la propia Delia Domínguez.

2 Rosa de Lima (1586-1617) es la primera santa del continente americano. Escribió un pequeño conjunto de poesías de temática religiosa.

3 Clorinda -quien en algunos textos también es llamada Clarinda- fue una poeta peruana que escribió bajo seudónimo. Su única obra conocida es Discurso en loor de la poesía (1608).

4 Se ha especulado en torno a la identidad de Amarilis. El investigador Carlos Milla Batres propuso en 1996 que se trataba de Gerónima de Garay Muchuy, una mujer nacida en Huánuco en 1555. Se trata de una mujer efectivamente de dos mundos, al ser nieta de Francisco de Garay, cuñado de Cristóbal Colón, e hija de Luisa Muchuy, quien fuera cacica de una tribu amazónica, los Mashcos. 
La Epístola a Belardo está compuesta por 335 versos, ordenados en 19 estrofas que siguen el modelo de la estancia. Al respecto, Georgina Sabat de Rivers plantea que hay un quiebre de la tradición, por cuanto este tipo de epístolas, que provienen de la línea horaciana, deberían haber estado escritas en tercetos encadenados y en versos sueltos. Sabat ve en esta innovación "conciencia de su condición femenina", debido a que querría diferenciarse de las epístolas horacianas cuyo tópico era la amistad masculina (1990: 464). Pero ¿cuál es el tópico de la carta de Amarilis? A primera vista pareciera que se trata de una carta de amor y de admiración a Lope de Vega. Hay varias marcas en el texto que acompañan esta lectura: "Oí, Belardo, tus conceptos bellos, / Tu dulzura y estilo milagroso" (v. 39-40); "Si el amarte sin verte fuere culpa" (v. 49); "No Belardo, Milagro han de llamarte, / Este es tu nombre, el cielo te lo ha dado, /Y amor que nunca tuvo paz conmigo / Te me presentó parte por parte" (v. 56-59). Pero eso sería quedarnos en una primera lectura. Al revisar de nuevo el poema, tengo presente las líneas de Mercedes Arriaga acerca de la doble alteridad a la que apelan las autobiografías escritas por mujeres ${ }^{5}$ : por un lado realizan una búsqueda de la voz propia a través de la escritura y, por otro, mantienen un registro -aunque sea limitado- del estereotipo impuesto por el discurso hegemónico (2001: 10). Consideremos entonces que la Epístola a Belardo fue publicada en 1621, momento en que la mujer todavía era considerada de segunda clase, y más aún si se trataba de una criolla; es la misma Amarilis quien deja explícita su condición de nacida en América, al relatar, por ejemplo, que "Dezir hazañas de mis dos abuelos / Que aqueste nuevo mundo conquistaron" (v. 171-172).

Por otra parte, El sol mira para atrás es una antología realizada por la misma Delia Domínguez y publicada en 2008. El libro está dividido en dos secciones: poesía y prosa. La primera incluye textos de los poemarios El sol mira para atrás, Pido que vuelva mi ángel, La gallina castellana y otros huevos y Clavo de olor, cubriendo un período que se extiende entre 1973 y $2004^{6}$. A continuación viene la segunda parte, titulada "Prosa parida sin corte de ombligo". A diferencia de la lírica, en la prosa no hay señas

5 Aunque no estoy estudiando el poema de Amarilis estrictamente como autobiografía, el análisis permite adelantar y configurar que el tema de la epístola es posicionarse como autora, por lo tanto, el enfoque que realiza Amarilis es sobre su experiencia.

6 Llama la atención el silencio que existe en la antología en torno a los primeros trabajos de Delia Domínguez: Simbólico retorno (1955), La tierra nace al canto (1958), Obertura siglo XX (1961), Parlamentos del hombre claro (1963) y Contracanto (1968). 
del período cubierto ni tampoco se aclara cuál es la fuente de los textos, con la excepción del discurso de la Academia Chilena de la Lengua, correspondiente al 25 de mayo de $1992^{7}$.

\section{Escribiendo desde el margen}

Cuando Raquel Chang-Rodríguez analiza las figuras de Amarilis y Sor Juana Inés de la Cruz, plantea lo inusual de que fueran mujeres escritoras, que supieran leer y escribir. Para Chang-Rodríguez, estas mujeres escribían desde una triple marginalidad: "first, their gender; second, their place of birth (if born in America from Spanish descent, they were considered inferior to native Spaniards); and third, their ethnic origin (if they were mestizas or Native Americans, then they occupied even a lower place in the social pyramid) $)^{8 \prime}(2005: 278)$.

No es difícil imaginar a una mujer del siglo XVII escribiendo desde la marginalidad. Lo interesante es la conciencia que Amarilis tiene de esta condición, como puede observarse en algunas marcas del texto, como la isotopía de lo oculto que podemos encontrar a lo largo de la carta: "Al fin es éste donde el Sur me esconde" (v. 37); "En este imperio oculto que el sur baña" (v. 145). Hay por un lado conciencia de estar en un mundo nuevo, poco conocido y que por la distancia que se establece entre la colonia y la metrópoli, ella también permanece oculta, sin descubrir. Hay una identificación entre ella y América. El continente es visto como territorio nuevo y difícil de habitar, requiere de trabajo y valentía. De la misma manera, ella es una mujer nueva, con la difícil tarea de plantarse como escritora y ser descubierta como tal.

Qué sucede entonces con Delia Domínguez (1931). En su poema "Papel de antecedentes" se describe como "Yo, católica mestiza / minimalista y campesina" (2008: 61). Vuelve a utilizar esas palabras en su discurso de incorporación a la Academia Chilena de la Lengua, titulado "Señales de una poesía mestiza en el paralelo $40^{\circ}$ sur". Género, lugar de nacimiento y origen étnico -la triple marginalidad de la que habla

7 Gran parte de los textos corresponden a semblanzas que escribió como colaboradora de la Revista Paula, de la que también fue jefa de redacción.

8 "[P]rimero, su género; segundo, su lugar de nacimiento (si nacidas en América de descendencia española, eran consideradas inferiores que los españoles nativos); y tercero, su origen étnico (si eran mestizas o nativas americanas, entonces ocupaban un lugar incluso más abajo en la pirámide social)". Traducción mía. 
Chang-Rodríguez- sigue presente. De la misma manera que Amarilis, Domínguez tiene conciencia del lugar del que escribe. Hay ciertamente algunas diferencias. La primera es que no necesita escribir desde una máscara como la que puede otorgar el seudónimo. En segundo lugar, puede explicitar su condición, a diferencia de Amarilis, que solo podía insinuarla. $\mathrm{Y}$ en tercer lugar, que las mujeres han ido conquistando espacios institucionales, como lo muestra el hecho de que Domínguez sea miembro de la Academia Chilena de la Lengua, algo que hubiera sido impensable en el Perú virreinal. Esa distinción podemos observarla en el poema "Mentadas americanas" de Delia Domínguez. En él, el sujeto lírico nos habla del silencio desde el cual ha hablado la mujer en América. El poema formado por una introducción y tres estrofas se centra en las mujeres americanas que permanecen en silencio, aquellas que no aparecen en la historia oficial, como María-Vitoca, quien "[e]ntre chupada y chupada / de Belmont King Size, hace de catequista / en la Sede Social de la aldea" (92) y Ana Torres, quien "aprendió a hablar sola, sin contestación / presente" (93). Son las mujeres de América que "escriben, sin saber leer y escribir" (Ibíd), como se lee en la postdata del poema.

Algunas mujeres, sin embargo, han podido romper el silencio que las sociedades americanas -basadas y construidas a partir de un discurso hegemónico masculino- le han impuesto a la mujer. Es así como el texto en prosa "Amante lírica y visible: América" se levanta como correlato de "Mentadas americanas". Es en dicho texto que Delia Domínguez construirá una genealogía de la literatura de mujeres, con la cual hablará de aquellas que efectivamente escribieron, que sabían leer y escribir y cuyas producciones literarias ayudaron a formar una lírica americana. La línea comienza con la madre tierra prehispánica, donde "había ya una suerte de literatura indígena transmitida por tradición oral de generación en generación" (160). La genealogía tendrá luego a Santa Rosa de Lima; Clorinda y Amarilis; Sor Juana Inés de la Cruz -que "comprendió que la palabra culta, parida del dolor y del entendimiento, era la mejor manera de comunicar estados vivenciales [...]" (162)-; y Gabriela Mistral ${ }^{9}$-"la voz femenina más alta de la lírica castellana contemporánea" (Ibíd).

9 Gabriela Mistral es apostrofada también en poemas de Delia Domínguez. Esto ocurre en el poema "Salgo a penar en las colinas" que tiene como intertexto a Poema de Chile. En los versos finales se lee: "Con las claves a salvo / soy digna de la nube y de la madre / ¿o no, Gabriela?" (2008: 87). 
Delia Domínguez explicita así su herencia literaria, y, al mismo tiempo, fija su posición de enunciación, la misma que se puede leer desde los primeros poemas de El sol mira para atrás: habla desde la tierra americana, desde la voz femenina, que no es romanticona, sino fuerte, cotidiana, construida desde la labor diaria y que busca su manifestación. Esa posición implica, por un lado, que es preciso escribir, porque de esa manera se saca a la mujer del olvido, y también que debe hablarse desde la propia experiencia. Cuando Ana María Cuneo realiza una lectura del poema "Hoja de vida"10, plantea que cuando uno escribe, queda expuesto, por cuanto "[e]n el acto de la transformación de la hoja en blanco en poema, el poeta va dejando rastros de su ser" (2004: 26). Mi propuesta con respecto a El sol mira para atrás es que Domínguez va dejando "rastros de su ser", o más bien, rastros de su voz ${ }^{11}$.

Amarilis también va dejando huellas de su voz en Epístola a Belardo. Pienso en los siguientes versos: "Quiero començar a darte cuenta / De mis padres y patria y de mi estado, / Porque sepas quién te ama y quién te escribe" (v. 127-129). De estas líneas es posible destacar varios puntos. En primer lugar, y siguiendo el tema de Amarilis como territorio nuevo, es interesante la conciencia de Perú como su patria, en vez de considerar a España como la patria. Recordemos que todavía faltan dos siglos para que los países americanos se independicen y, sin embargo, ella tiene conciencia de que son una nación distinta e independiente. En "Amante lírica y visible: América", Domínguez escribe: "La literatura, o la oración lírica, no vino a Hispanoamérica con el arribo de los conquistadores; ella estaba desde antiguo, en el espacio interminable de la meseta andina, en la orilla de los ríos alimentadores de cuerpos y de almas" (159). A la luz de ese texto -al que considero entonces como un hipograma ${ }^{12}-$, Delia Domínguez me permite otra lectura de la conciencia que tiene Amarilis de que Perú es su patria: Perú no es solo una nación independiente, también es una patria que posee una literatura propia, dentro de lo cual hay que destacar que esta patria -y por consiguiente la patria-literaturano es conformada solo por los hombres, sino también por las mujeres.

10 Este poema pertenece a Huevos revueltos (2000), que aunque no aparece en la selección de El sol mira para atrás, permite aproximarse a la perspectiva personal de la obra de Domínguez.

11 Me inclino por la utilización de voz, por cuanto es la voz lírica la que encontramos en los poemas y no rastros efectivos del ser desde un punto de vista ontológico.

12 Hipograma en el sentido de lo planteado por Riffaterre: un texto otro desde el cual el lector analiza el poema y le da sentido (1984). 
Domínguez no hablará en forma exclusiva de Perú, sino de América en su totalidad, observando que esta tierra sigue dándole forma a su voz, como menciona en otro poema: "Y yo con 500 años sacando pecho / desde el gran diluvio hasta este otro diluvio / hilvanada de cantos y espantos como enagua de vieja: / caldo de cultivo" (68).

Cuando Amarilis dice "Quiero començar a darte cuenta / De mis padres y patria y de mi estado, / Porque sepas quién te ama y quién te escribe" (v. 127-129), también hace el reconocimiento de su propio cuerpo como patria, es decir, como dueña de sí misma. Contrasto esto con las siguientes palabras: "La mujer [...] está presente total y físicamente en su voz, y su obra escrita no es más que la extensión del acto de hablar, reflejo de su propia identidad" (Moi, 1988: 123). Efectivamente, Amarilis en vez de apelar a la visión y a que Lope y los lectores leamos, apela al oído y a que escuchemos sus palabras. En sus versos, ella se expone de cuerpo entero. Me parece interesante que el concepto de cuerpo como patria aparezca en los versos introductorios al objetivo que considero principal en su epístola: su posicionamiento como mujer y autora. La intención está explícita: "[p]orque sepas quién te ama y quién te escribe"; es decir, el objetivo principal de Amarilis no es realizar una alabanza de Lope de Vega -aunque lo alabe-, sino presentarse a sí misma como mujer que ama, pero, más importante, como mujer que escribe. Ya en el comienzo de la epístola había marcas que hablaban de ella. Por ejemplo, se considera un "alma osada" (v. 28), y por supuesto que es una actitud osada, siendo mujer y americana, querer establecerse como escritora. Más adelante, declarará que no es el amor mundano el que le interesa, sino dedicarse a las letras, para lo cual establecerá un contrapunto con su hermana Belisa. En ese sentido, mientras las bondades de su hermana "[a]l fin todas han sido mereçidas / Con alegre Himeneo / De un joven venturoso que en trofeo / A su fortuna y vencedora palma / Alegre la rindió prendas del alma" (v. 205-209), Amarilis ha "sido a dulces Musas inclinada" (v. 202). Las letras son una labor de índole más bien sublime para Amarilis. Esa percepción proviene ya de los versos de admiración a Lope; así, por ejemplo, le dice "Que es patria tuya el cielo" (v. 98), de cuya lectura podemos colegir que merece el cielo por su condición de escritor. Concordantemente también llamará a los versos de Lope "divinos concetos" (v. 120). Así, es tal la dedicación que ella otorga a las letras, que asume el ser escritora como un asunto que involucra su forma de vida por completo. Así, siempre en contraposición a su hermana, escribirá: "Yo 
siguiendo otro trato / Contenta vivo en limpio celibato / Con virginal estado / A Dios con gran afecto consagrado" (v. 210-213).

\section{Estrategias de posicionamiento}

Consagrarse a ser escritora, sin ocultar que se es mujer, es una tarea para almas osadas. En ese sentido, Amarilis no ocultará que esa decisión es difícil de mantener y, de hecho, se encomienda a Dios: "Y espero en su bondad y su grandeza / Me tendrá de su mano / Guardando inmaculada mi pureza" (v. 214-216). Está hablando de su virginidad, pero dicha condición está asociada indisolublemente a la de ser escritora, por cuanto no solo decide dedicarse a la escritura, sino consagrarse a la escritura. Teniendo conciencia de la situación marginal desde la que escribe por ser mujer, dirá que "Temerosa y cobarde está my pluma" (v. 220), al tiempo que describe su decisión de dirigirle la epístola a Lope como si fuera un atrevimiento. Amarilis habla a momentos desde un ánimo de humildad, de lo cual encontramos marcas en el texto, como cuando se refiere a "mi Musa rústica" (v. 310) e incluso cuando le pide a Lope que lea "[c]on singular paciencia mis simplezas". Veo aquí no que ella considere inferior su escritura comparada con la de Lope, sino una estrategia de posicionamiento, debido a que lo que busca en Lope de Vega, más que un amor platónico, sería un padrino para sus versos, algo que, de hecho, consigue, puesto que es el español quien publica la epístola. Digo que se trata de una estrategia, en que aparenta rebajarse ante el maestro, por cuanto en la misma carta ella toma una posición de igual a Lope, o incluso de estar por sobre él, al darle consejos referentes a centrarse en su oficio (como ella que se ha consagrado a esto), en vez de perder el tiempo en cosas mundanas. Así le dice: "Pues, peregrino mío, / Vuelve a tu natural pongante brío / No las murallas que ha hecho tu canto / en Tebas engañosas, / Mas las eternas que te importan tanto" (v. 104-108).

En el artículo "Tretas del débil", Josefina Ludmer ser refiere a las estrategias de Sor Juana Inés de la Cruz para defenderse y posicionarse en la Respuesta de Sor Juana a Sor Filotea. Declarar a la musa como rústica y a la escritura propia como simple o imperfecta -como hace Amarilis-, se enmarca también en ese concepto de las tretas que debe usar el débil -la mujer en su posición marginal y de silencio obligado- para decir sin decir que piensa y escribe (Ludmer: 1984). Parecería que ser mujer es estar en un vaivén entre el silencio y el habla. En el poema "Básica", Delia 
Domínguez escribe: "Sin decir esta boca es mía / yo digo: esta boca es mía / porque la tierra hace hablar sin habla" (2008: 75). Pareciera enmarcarse dentro del "[d]ecir que no se sabe, no saber decir, no decir que se sabe, saber sobre el no decir", que la crítica argentina reconoce en el texto de Sor Juana que mencionaba anteriormente (1984: 1). Domínguez, como Amarilis, también apelará a la humildad en su discurso de la Academia Chilena de la Lengua: "Y confieso con humildad toda la influencia, todas las cargas, las sangres revueltas de mi latitud colonizada" (117). Entre dichas influencias, Domínguez ha citado desde Rilke a Goethe, con lo cual se ubica a sí misma a la altura de hombres reconocidos en el canon literario: tiene muy clara su posición en el campo de la literatura. De la misma forma, Amarilis se ponía a la altura de otro autor canónico: Lope de Vega.

En Amarilis podemos encontrar otro momento en que plantea la conciencia que tiene del valor de su escritura y de su condición de mujer-autora, en los versos en que se traza más fuerte y valiente que cualquier hombre: "Mas que mi Musa rústica se atreva / A emprender el assumpto a que me atrevo, / Hazaña que cien Tasos no emprendieran, / Ellos al fin son hombres y temieran, / Mas la muger que es fuerte / No teme alguna vez la misma muerte" (v. 310-315). La mujer fuerte no le teme a la muerte, y menos a lanzarse a la escritura, aunque sea una actividad tradicionalmente ligada al ámbito masculino. En Domínguez no hay una comparación antagónica como la que plantea Amarilis en los versos mencionados. Sin embargo, sí plantea la fuerza de la mujer desde el momento de su nacimiento. Así dirá, por ejemplo: "Eso sí. Me confieso / vulnerable como sietemesina / pero, a la vez, fuerte como olla de tres patas" (70) y "Estaba escrito. / Para nacer debía tocar fondo" (99). Se podría decir que ha sido una condición vulnerable -la de ser marginal, tal vez-la que la ha vuelto más fuerte.

Isabel Allende, en uno de los prólogos que se encuentran en la antología de Domínguez, dice sobre la poeta: "Su madre murió cuando tenía cinco años y le dejó un vacío tan pasmoso, que está convencida de que no sería poeta si ella hubiera vivido" (81). Esas palabras se relacionan con la idea ya planteada de que desde la vulnerabilidad surge la fuerza; tal como desde el silencio, surge la escritura. Pero también sugiere otro aspecto: para qué escribir. Pienso en la epístola de Amarilis y planteo que la intención no era que permaneciera oculta, por el contrario, ella quiere ser descubierta, pero no solo ante Lope de Vega ("descubrirme a ti", dice 
en el verso 45), sino ante la comunidad intelectual y lectora. Por eso, ella lanza sus versos al mar. Reconoce que serán una novedad, al identificarlos como "fruta nueva" (v. 328) y que serán leídos: "Os vendrán a provar, aunque sin gana, / Y verán vuestro gusto bronco y tardo" (v. 329-330). Al respecto, me parece que no deja ir a sus versos -"Navegad, buen viaje, hazed la vela" (v. 334) escribirá Amarilis-, en los límites de su época, sino que al enviarlos a navegar es consciente de un sentido de trascendencia: ella quiere que sus versos sean honrados para la posteridad, teniendo presente que ella es mujer, americana y escritora.

¿Recoge alguien esos versos? Ya lo vimos, Delia Domínguez ubica a Amarilis en esa herencia literaria que la ha convertido en la mujerautora que es hoy. Decía al comienzo de este trabajo que Amarilis escribe desde el margen geográfico, al estar situada en Perú con respecto a España. Reconoce al sur como escondido y quiere ser descubierta. También Domínguez quiere ser descubierta. Podríamos considerar que su inclusión en la Academia Chilena de la Lengua es una instancia que la visibiliza. De hecho, ella dice en su discurso: "gracias por mirar hacia mi Finis Terrae, por descorrer la niebla de los lagos, por encontrarme entre los alfabetos de la lluvia y pasarme por el Civil para cambiar mi estado de hija natural, al de hija reconocida en las fojas archivadas de la literatura" (108). Domínguez también escribe desde el margen, desde ese paralelo $40^{\circ}$ sur, desde su condición mestiza, desde su género femenino, y es precisamente esa escritura la que la descubre, no la institución en sí, sino los versos y prosas que ella ha registrado y que han salido más allá de sus manos, tal como la epístola de Amarilis. ¿Para qué escribir entonces? Es más que dar expresión al talento o a una inquietud literaria, escribir es una acción para salir del silencio, dejar de ser invisible, y convertirse en un cuerpo muy presente a través de una escritura ligada a la experiencia de mujer.

\section{Conclusiones}

Me propuse en este trabajo establecer líneas de unión entre Amarilis y Delia Domínguez, partiendo de la premisa de que ambas escribían desde un posicionamiento y conciencia de ser mujer-autora. A través del análisis de sus escrituras, he reseñado un camino que muestra que, efectivamente, ambas tienen plena conciencia de su condición, de la marginalidad desde la cual escriben y del sentido de trascendencia que 
tienen sus escrituras al momento de dejarlas ir con un destino claro: ser conocidas.

Me interesaba vincular a estas dos mujeres y poetas de tiempos tan apartados, debido a que ambas están interesadas en el tema de la mujer y su condición de autora, esto es, que escriben con conciencia de ser mujeres y que problematizan la condición de silencio en que la mujer ha sido mantenida. Estas dos poetas escriben en contra de ese silencio, para tener voz y porque tienen voz. Aunque situadas con siglos de distancia, puedo ver en sus escrituras que aunque los discursos femeninos se han ido haciendo visibles -como la misma Domínguez sostiene-, todavía la mujer escribe desde el margen. Podríamos pensar entonces en otras mujeres que han escrito y siguen escribiendo desde el margen, y también en todas aquellas que permanecen invisibles, cuyos escritos se perdieron o falta que sean recogidos por la crítica y los lectores. Porque la finalidad de estas escritoras es ser leídas - u oídas-, tal como lo planteaba Amarilis en el siglo XVII al decirle a sus versos, sus palabras: "Navegad, buen viaje, hazed la vela".

\section{Bibliografía}

Amarilis. Epístola a Belardo.

Arriaga, Mercedes (2001). Mi amor, mi juez. Alteridad autobiográfica femenina. Barcelona: Anthropos.

Chang-Rodríguez, Raquel (2005). "Gendered voices from Lima and Mexico: Clarinda, Amarilis, and sor Juana". En A companion to the literatures of Colonial America. Estados Unidos: Blackwell Publishing.

Cuneo, Ana María (2004). "Delia Domínguez: experiencia y canto". En Revista Chilena de Literatura 64: 5-27.

Domínguez, Delia (2008). El sol mira para atrás. Antología personal de poesía y prosa. Santiago: Catalonia.

Ludmer, Josefina (1984). “Tetras del débil”. En Patricia González y Eliana Ortega (eds), La sartén por el mango. Encuentro de escritoras latinoamericanas. Río Piedras, Ediciones Huracán, 1984. Recuperado el 20 de junio de 2011. En 


$$
\begin{aligned}
& <h t t p: / / \text { www.josefinaludmer.com/Josefina_Ludmer/ } \\
& \text { Sor_Juana.html/ }
\end{aligned}
$$

Moi, Toril (1988). Teoría literaria feminista. España: Ediciones Cátedra.

Riffaterre, Michel (1984). Semiotics of poetry. Bloomington: Indiana University Press.

Sabat de Rivers, Georgina (1990). "Amarilis: Innovadora peruana de la epístola horaciana". Hispanic Review Vol. 58, N 4 , 455-467.

Vázquez, M. Ángeles (19 de febrero de 2009). "Epístola de Amarilis a Lope de Vega". Rinconete, revista del Centro Virtual Cervantes. Online. Recuperado el 29 de junio de 2011. En <http://cvc.cervantes.es/el_rinconete/ anteriores/febrero_09/19022009_02.asp> 